\title{
Modos de ler Filosofia: uma conversa com iniciantes e iniciados
}

\author{
Ester Maria Dreher Heuser ${ }^{1}$
}

Resumo: Com uma escrita direta ao leitor, como se fosse uma conversa com um iniciante ou iniciado em Filosofia, o artigo ocupa-se do gesto que qualquer um que se aproxima dela realiza. Trata-se do gesto de ler. Após tematizar a invenção da escrita e das bibliotecas, aborda alguns elementos próprios aos modos de ler Filosofia, quais sejam: descobrir os benefícios da solidão; ler devagar, atenta e desconfiadamente; ler levantando a cabeça para, então, quiçá, chegar a pensar - o maior desafio para qualquer um que deseja se relacionar com a Filosofia.

Palavras-chave: ler; escrever; pensar.

\section{Modos de leer Filosofía: una conversación con iniciantes e iniciados}

Resumen: Con una escritura directa al lector, como si fuese una conversación con un iniciante o iniciado en Filosofía, este artículo se ocupa del gesto que cualquiera que se aproxima de ella realiza. Se trata del gesto de leer. Después de tematizar la invención de la escritura y de las bibliotecas, aborda algunos elementos propios de las formas existentes de leer filosofía, a saber: descubrir los beneficios de la soledad; leer lenta, atenta y desconfiadamente; leer levantando la cabeza para, entonces, quizás, llegar a pensar - el mayor desafío para cualquiera se relaciona con la filosofía.

Palabras clave: leer; escribir; pensar.

\section{Sobre escrita e bibliotecas}

Certamente já ouviste falar que "para fazer Filosofia é preciso gostar de ler, e de ler muito", ou "quem faz Filosofia vive 'dentro' dos livros", "mora em bibliotecas". Ouviste ou ouvirás que quem faz Filosofia quase sempre refere filósofos do passado e se utiliza de livros desses filósofos para chegar a escrever algo que mereça ser lido. Afinal, já estamos cerca de 2600 anos distantes de Tales de Mileto, o primeiro filósofo. Desde lá, muita coisa foi pensada, escrita, editada e guardada em bibliotecas. Estes lugares que, sem exagero, podemos considerar os mais "sagrados" que a humanidade foi capaz de criar. As bibliotecas, talvez, sejam a

\footnotetext{
${ }^{1}$ Doutorado em Educação pela Universidade Federal do Rio Grande do Sul, Brasil(2008). Professora Adjunta da Universidade Estadual do Oeste do Paraná, Brasil - E-mail: esterheu@hotmail.com
} 
prova palpável da imensa generosidade da cultura². Mas, se bibliotecas existem é porque, primeiro, a escrita foi inventada. O que se deu, segundo a mitologia egípcia contada por Sócrates, graças ao deus Thoth que inventou a escrita, dentre outros grandes feitos que mudaram o futuro da humanidade, tal como nos relata Platão, em seu diálogo Fedro:

- Sócrates: Bem, ouvi dizer que Thoth inventou os números e o cálculo, a geometria e a astronomia, o jogo de damas e os dados, e tiambém a escrita. Naquele tempo governava todo o Egito, Tamuz, que residia ao sul do país, na grande cidade que os egípcios chamam Tebas do Egito. Thoth foi ter com ele e mostrou-lhe as suas artes, dizendo que elas deviam ser ensinadas aos egípcios. Mas o outro quis saber a utilidade de cada uma, e enquanto o inventor explicava, ele censurava ou elogiava, conforme essas artes the pareciam boas ou más. Quando chegaram à escrita, disse Thoth: Esta arte, caro rei, tornará os egípcios mais sábios e Ihes fortalecerá a memória; portanto, com a escrita inventei um grande auxiliar para a memória e a sabedoria. Responde Tamuz: Grande artista Thoth! Não é a mesma cousa inventar uma arte e julgar da utilidade ou prejuízo que advirá aos que a exercerem. Tu, como pai da escrita, esperas dela com o teu entusiasmo precisamente o contrário do que ela pode fazer. Tal cousa tornará os homens esquecidos, pois deixarão de cultivar a memória; confiando apenas nos livros escritos, só se lembrarão de um assunto exteriormente e por meio de sinais, e não em si mesmos. Logo, tu não inventastes um auxiliar para a memória, mas apenas para a recordação. Transmites para teus alunos uma aparência de sabedoria, e não a verdade, pois eles recebem muitas informações sem instrução e se consideram homens de grande

\footnotetext{
${ }^{2}$ Não se trata de "sagrado" no sentido religioso, transcendente, místico, mas no sentido de respeito que um lugar "precioso", raro, merece ter. O genial escritor argentino, Jorge Luís Borges, bibliotecário por profissão, escreve um conto em homenagem às bibliotecas do mundo e imagina que, depois de sua morte, habitaria uma ampla e eterna Biblioteca. Isso e muito mais sobre os livros e esse lugar que, para mim, é "sagrado", pode ser lido em sua "Biblioteca de Babel", disponível em: <http://biblio3.url.edu.gt/Libros/borges/babel.pdf>, último acesso em 18/05/2015.
} 
saber, embora sejam ignorantes na maior parte dos assuntos. Em consequência, serão desagradáveis companheiros, tornar-se-ão sábios imaginários ao invés de verdadeiros sábios.

- Fedro: Com que facilidade, Sócrates, inventas histórias egípcias assim como de outras terras, quanto isso te apraz!

- Sócrates: O uso da escrita, Fedro, tem um inconveniente que se assemelha à pintura. Também as figuras pintadas têm a atitude de pessoas vivas, mas se alguém as interrogar conservar-se-ão gravemente caladas. $O$ mesmo sucede com os discursos. Falam das cousas como se as conhecessem, mas quando alguém quer informar-se sobre qualquer ponto do assunto exposto, eles se limitam a repetir sempre a mesma cousa. Uma vez escrito, um discurso sai a vagar por toda parte, não só entre os conhecedores, mas também entre os que $o$ não entendem, e nunca se pode dizer para quem serve e para quem não serve. (PLATÃO, 1981, p. 145-152 [Os negritos são nossos; citação com vários recortes não assinalados]).

Porque acreditava na força, vitalidade e proficuidade do diálogo para o desenvolvimento do pensamento que busca o Verdadeiro, o Bem e o Belo, Sócrates preferia a palavra viva que, para ele, só poderia existir por meio da conversa frente a frente, com aqueles que ele interrogava pelas ruas e praças atenienses. Para a sorte da humanidade, nesse quesito, Platão não levou seu mestre a sério e registrou suas ideias, pontos de vista e concepções de mundo, fazendo de Sócrates o protagonista de quase todos os seus Diálogos. Temos a nosso alcance, também graças aos que preservaram os registros platônicos e aos tradutores do grego antigo, nas bibliotecas e agora na internet - essa grande biblioteca mundial - acredita-se, praticamente todos os escritos de Platão. A escrita, tal como profetizou Thoth, tornou-se "um grande auxiliar para a memória e a sabedoria", mas, a meu ver, muito mais do que isso...

Já Aristóteles, o discípulo mais genuíno de Platão, foi ainda mais longe: além de escrever muito $^{3}$ - segundo o filósofo latino Cícero, suas obras eram "o rio de ouro

\footnotetext{
3 Conhece-se uma parte mínima dos escritos de Aristóteles, uma vez que quase tudo se perdeu, talvez com o incêndio da Biblioteca de Alexandria. Talvez, não se sabe, ao certo. Sobre a perda dos escritos de Aristóteles ver o interessante texto do venezuelano Fernando
} 
da eloquência" (Cf. BÁEZ, 2000, p. 1) -, ele foi também um grande colecionador de livros, talvez, o primeiro "bibliófilo" do ocidente. Segundo o geógrafo Estrabón de Amasia, Aristóteles foi quem ensinou aos reis do Egito a organizar uma biblioteca. Com alguns riscos, pode-se afirmar que um deus egípcio inventou a escrita e que, um homem grego, por ser digno dessa herança divina, inventou a Biblioteca.

Ao menos desde Aristóteles, fundador do Liceu, ou do Perípato, (335/334 a. C.), é que a Filosofia está ligada à leitura. Desde sua época de estudante, Aristóteles foi chamado de "O Leitor", gastou fortunas em obras advindas de distintos lugares, que versavam sobre os mais variados temas. Daí ser comum afirmar-se que para alguém que queira tornar-se Filósofo, precisa interessar-se por qualquer tipo de assunto, afinal, quanto mais conhecermos, maior será a possibilidade de estabelecermos relações e maior será o risco de chegarmos a pensar algo, a ter uma ideia. Estima-se que o acervo da biblioteca deixada por Aristóteles, no Liceu, era composto de cerca de 10.000 papiros, sendo que, de autoria de Aristóteles eram mais de 382 obras, contidas em mais de 1005 rolos de papiro, além de outros originais ou cópias de autores da escola peripatética (colegas de Aristóteles que trabalhavam no Liceu) e papiros de escritores antigos ou contemporâneos ao filósofo4 (Cf. BAEZ, 2000).

Báez: "Los escritos perdidos de Aristóteles" (2000, disponível em: <http://serbal.pntic.mec.es/ cmunozl 1/perdido.pdf>). Neste texto, além das descrições das idas e vindas dos escritos de Aristóteles, após a sua morte, o autor mostra, um pouco, os perigos que os papiros de Aristóteles, bem como as aulas de Filosofia do Liceu, representavam para a Grécia, pós Alexandre, o Grande, ao ponto de afirmar que "um líder democrático" propôs a proibição do ensino da Filosofia em Atenas, com vistas a fechar o Liceu que chegou a contar com mais de dois mil estudantes. Como se vê, desde sempre a Filosofia foi "perigosa" para os poderes instituídos... Báez é um notável investigador da destruição de livros e bibliotecas e fez parte da comissão que investigou, no Iraque, a destruição dos bens culturais iraquianos, dentre eles muitas bibliotecas que abrigavam escritos milenares, verdadeiro memoricídio feito pelos Estados Unidos da América. Sobre o "perigo" que uma biblioteca pode representar, vale ler a entrevista desse pesquisador. Disponível em: <http://gredos.usal.es/jspui/bitstream/10366/1 19235/1/EB18_N152_P29-33.pdf>, última consulta em 18/05/2015, às 16h15min.

${ }^{4}$ Para ter uma ideia de como eram as bibliotecas na antiguidade, sugiro o filme Agora (traduzido no Brasil por Alexandria), dirigido pelo espanhol Alejandro Amenábar (2009); além 
Arrisco dizer que, na Filosofia, a partir de Aristóteles, a ideia frente ao uso da escrita se alterou, pois deixou de ser concebida como mera "repetição da mesma cousa", tal como concebia Sócrates. Preocupado com a educação dos cidadãos, Aristóteles defendeu, em sua Política, que "escrever e ler são úteis aos negócios e à economia doméstica e à aquisição de conhecimento e às várias atividades da vida em uma cidade"5 $(1988,1338$ a). Por isso, recomendava que todos os futuros cidadãos aprendessem a ler e a escrever, dentre outras coisas úteis. Além dessas funções práticas que servem a cada um de nós para nos situarmos no mundo, adquirirmos conhecimentos para aprendermos, conseguirmos um emprego, passarmos em concursos, "ganharmos a vida", enfim, a leitura - e a escrita - serve também para ampliar o mundo e, sem exagero, criar mais vida em nossas próprias vidas. Isso porque, em meu ponto de vista, a cada vez que lemos algo que nos possibilita fazer relações, pensar o que não pensávamos e atribuir novos sentidos ao que já pensávamos, nossa compreensão de mundo se expande e nossa vida se torna mais complexa, por isso, mais interessante e, talvez, mais válida de ser vivida.

Apesar de leitura e escrita estarem sempre juntas - afinal, se não escrevemos durante, antes ou depois da leitura, é certo que lemos a escrita de alguém e, se escrevemos, lemos, ao menos, a nossa própria escrita -, neste texto que o leitor tem diante de si interessa-nos abordar alguns elementos próprios aos modos de ler essa tal Filosofia. Embora não exista "O modo certo de ler Filosofia", ainda que me pareça muito interessante e, talvez, mister, que cada um crie seu de ilustrar uma biblioteca, o filme apresenta, como protagonista, a filósofa, matemática e astrônoma Hypatia. Segue uma sinopse do filme: "Sob o domínio Romano, a cidade de Alexandria é palco de uma das mais violentas rebeliões religiosas de toda história antiga. Judeus e cristãos disputam a soberania política, econômica e religiosa da cidade. Entre o conflito, a bela e brilhante astrônoma Hypatia (Rachel Weisz) lidera um grupo de discípulos que luta para preservar a biblioteca de Alexandria. Dois deles disputam o seu amor: o prefeito Orestes (Oscar Isaac) e o jovem escravo Davus (Max Minghella). Entretanto, Hypatia terá que arriscar a sua vida em uma batalha histórica que mudará o destino da humanidade".

5 Preocupação essa que está presente até hoje nas políticas para a formação dos cidadãos, algumas com mais, outras com menos êxito, conforme podemos perceber nos dados do IDEB (Índice de Desenvolvimento da Educação Básica). 
próprio modo de ler, há alguns elementos necessários para ler Filosofia que estão presentes em qualquer maneira inventada de ler esse tipo de escritura. Talvez os elementos que se seguem possam ser considerados também para fazer outros tipos de leitura, mas são, ao menos, pertinentes para a leitura de um livro de Filosofia. São eles: descobrir os benefícios da solidão; ler devagar, atenta e desconfiadamente; ler levantando a cabeça.

\section{Descobrir os benefícios da solidão}

Biblioteca é local de silêncio - seja ela de lata, composta de uma só estante com poucas dezenas de livros e gibis, situada na beira da rua, em frente a uma indústria de alimentos, como é o caso específico na cidade onde moro, no Paraná; seja ela imensa, imponente e cheia de raridades, como a Biblioteca do Congresso Americano, com 140 milhões de obras. Local de silêncio também é uma aula de leitura, ou outro ambiente qualquer em que alguém se põe a ler um livro. Este silêncio, contudo, é acompanhado, além do livro, de um tipo especial de solidão. Não simplesmente daquela solidão que tem o sentido de isolamento que o estudo atencioso requer, o sentido de "ficar sozinho", mas de uma "solidão povoada" e, algumas vezes, feita, paradoxalmente, de um "silêncio bastante ruidoso" advindo das ideias, problemas, conceitos e personagens criados pelo autor, assim como de outras tantas "vozes" que se fazem presentes, a partir de experiências de vida e de leituras anteriores do leitor. Se o leitor encontra essa solidão e entrega-se a ela, encontrará seus benefícios para sua própria vida, ao ponto de desejá-la e, seguidamente, não querer fazer outra coisa, nem estar em lugar algum, senão aquele em que o tempo e o espaço da ordem dos dias estão suspensos. Será o feliz encontro entre duas solidões - a do leitor e a do escritor, ainda que o conteúdo do livro e sua forma de expressão incomodem, angustiem, irritem o leitor, porque põem em questão os "pensamentos acostumados", os valores, as crenças e as verdades que compõem a sua vida. Feliz porque aumentará a potência de pensamento, do entendimento, da imaginação e, assim, ampliará o mundo do leitor. Para Paul Auster, escritor americano contemporâneo, ainda vivo, o livro é a própria imagem da solidão, aliás, ele é produto da solidão. Em suas palavras, retiradas da obra $A$ invenção da solidão, um livro é: 
[...] um objeto tangível, que se pode levantar, baixar, abrir e fechar, e suas palavras representam muitos meses, quando não muitos anos, da solidão de um homem, de tal modo que, para cada palavra que lemos em um livro, podemos dizer a nós mesmos que estamos diante de uma partícula daquela solidão. Um homem senta-se sozinho em um quarto e escreve. Quer fale o livro de solidão, quer fale de companheirismo, é forçosamente produto da solidão (AUSTER, 1999, p. 153).

Ao lermos um livro, é como se entrássemos na solidão daquele que escreveu, e ela se transformasse em nossa própria solidão. Mas, dirá Auster, "Isso é impossível. Pois, uma vez que a solidão abre uma brecha, uma vez que outro adota essa solidão para si, não é mais solidão. Mas uma espécie de companheirismo" (1999, p. 153) - algo que se aproxima do que eu chamei de "solidão povoada". Afinal, ainda que estejamos sozinhos em nosso quarto, ou frente à escrivaninha de uma biblioteca, ou, ainda, embaixo de uma árvore, ao abrirmos um livro, já somos ao menos dois - autor e leitor - partilhando essa paradoxal solidão.

\section{Ler devagar, atenta e desconfiadamente}

Para que possamos usufruir todos os benefícios dessa "solidão povoada"

junto a um livro de Filosofia, para ler um filósofo, aproximar-se dele, entrar na intimidade de suas ideias e ter prazer na leitura, é preciso ler devagar, com o espírito atento e desconfiado. Essa desconfiança, no entanto, ao menos no primeiro momento da leitura, não é relativa ao que o filósofo escreveu, mas a ti mesmo, a tua primeira impressão, às relações com aquilo que tu estás acostumado a pensar. Com vagarosidade e atenção, lê o texto e desconfia daquilo que pensas estar entendendo; presta atenção nos sentimentos que o texto provoca e nas ideias particulares que surgem em ti, com essa leitura. O melhor para a aproximação às ideias do filósofo seria ler o livro inteiro, uma primeira vez, como se estivesses lendo um romance; além de teres uma noção geral do que se trata o livro, tu estarás conhecendo a linguagem do autor. Depois, lê outra vez, sempre devagar, com um lápis na mão, sobre a mesa um bloco de notas, um dicionário de português, ou da 
língua na qual o texto está escrito e, se conseguires, tem por perto um dicionário de Filosofia', e:

a) observa a ideia geral do filósofo, aquela da qual ele partiu. Essa poderá ser a resposta para as questões: o que o fez produzir sua filosofia? Qual o sentimento que o moveu a produzir sua obra e suas ideias particulares? Responder essas questões pode ser feito se tu investigares o que o filósofo mais detestava no mundo. Ou, contra o que e contra quem ele pensou e escreveu? Isso porque, para mim, um filósofo, ao fazer sua filosofia, vai contra algumas ideias, situações, condições de vida e de pensamento, a favor de outras, muitas vezes, que ele mesmo cria. Para isso, se o filósofo não declara explicitamente o que mobilizou seu pensamento para escrever - os filósofos não contam tudo em suas obras -, tu terás que, por um momento, abandonares o livro e buscares em outros, ou mesmo na internet, alguns elementos que distintos leitores desse filósofo já levantaram. Tais leitores costuma-se chamá-los de "comentadores", ou "especialistas no filósofo tal" - sim, há pessoas que passam sua vida lendo e escrevendo sobre o que filósofos pensaram;

b) em seguida, relembra aquele sentimento inicial que a leitura provocou, quais foram as ideias particulares dele provindas e questiona-te: quais as ideias gerais e cerebrais - não mais sentimentais e sim racionais - que o filósofo produziu? Como responder a isso? Lendo o próprio filósofo, comparando-o a ele mesmo. Uma estratégia eficaz é anotar as primeiras impressões, marcar as razões que te levaram a elas;

c) não te abandones, não sejas preguiçoso, segue lendo e comparando. Prossiga! Observa no texto quais as ideias que sempre retornam, quais as expressões que se repetem, quais os conceitos que vêm e vão - isso acontece porque são caros ao filósofo, porque respondem ao seu problema -, o que insiste e persiste na obra.

Se conseguires fazer isso tudo, tua aproximação ao pensamento do filósofo já será expressiva. Até aqui a leitura terá sido o que podemos chamar de uma "respeitosa leitura de instrução", ela possibilitará a ti falares sobre os pensamentos

6 Um bom Dicionário de Filosofia está disponível aqui: <http://www.portalconservador.com/livros/Jose-Ferrater-Mora-Dicionario-de-Filosofia.pdf $\geq$ (último acesso em 21/05/2015, às 16h20). 
do filósofo, fazeres um bom trabalho de Filosofia $e$, de repente, até uma monografia. Mas se, para ti, aquilo que o filósofo escreveu faz sentido, se tornou interessante e te ajuda a pensar, segue o próximo item porque, de repente, esse livro, esse filósofo é quem te ajudará a pôr a Filosofia em curso7. Caso contrário, pare por aqui...

d) segue lendo, volta às páginas quantas vezes forem necessárias e questiona-te: até onde vai o filósofo? Quais são os seus limites? A partir daqui, a desconfiança será tua também em relação ao que lês, não só ao que tu, enquanto leitor atento, entendes. Delimita o pensamento do autor a fim de compreendê-lo melhor: um filósofo não pensou em tudo absolutamente! Ainda que em seu sistema tenha desejado abarcar o Todo! Relê o filósofo até que se torne possível analisá-lo. Observa os seus procedimentos de escrita, dá atenção aos exemplos que ele recorre. Esse procedimento te levará a conhecer o filósofo com prazer. Sim, isso é possível, encontrar prazer no interstício que há entre o teu pensamento e o do filósofo, pois, como afirma Émile Faguet, no livro A arte de ler:

[...] ao dominar o procedimento de um autor, você pode sempre voltá-lo contra ele mesmo. E isso é, a princípio, um jogo divertido, portanto um prazer. Mas não é só um jogo, é assenhorear-se de seu autor até o fundo. É como que se apoderar de sua raiz, do germe de onde sua obra saiu e de onde poderia sair, sem dúvida, idêntica, mas numa outra direção. É, na verdade, conhecê-lo bem (FAGUET, 2009, p. 19).

Se tu chegares até aí, porém, algo de diverso já estará em processo, um novo movimento terá de ser dado...

\footnotetext{
7 Um filósofo do século XX, Martin Heidegger, no curso Introdução à Filosofia (2008), defende que o simples fato de sermos humanos já significa filosofar. A Filosofia está no ser humano, mas ela está "como que dormindo em nós", intrincada, agrilhoada. É preciso despertá-la, torná-la livre, pô-la em movimento, daí a ideia de que se trata de "pôr o filosofar em curso, deixar a filosofia acontecer em nós". Como fazer isso? Heidegger dirá que se ater à história da Filosofia é importante, mas não o suficiente, pois não basta conhecê-la para filosofar, aliás, ele afirmará que essa é a causa de uma grande ilusão: "a posse de conhecimentos sobre filosofia é a principal causa da ilusão de que com isso estaríamos alcançando o filosofar" (2008, p. 05). De minha parte, considero que o próximo elemento indicado no texto para ler essa tal Filosofia, pode romper com a ilusão e, efetivamente, pôr o filosofar em curso.
} 


\section{Ler levantando a cabeça}

Esse prazer de pensar ao ler só é possível na medida em que se acrescenta à leitura vagarosa e desconfiada aquilo que Roland Barthes chamou de "ler levantando a cabeça" (2004, p. 26 [o itálico é do autor]). Quando se passa a levantar a cabeça em meio à leitura, ela ultrapassa sua condição de instrução e torna-se irrespeitosa, na medida em que é interrompida com frequência; interrupção provocada por afluxos de excitações, associações e ideias que passam a gerar a produção e a realização da "leitura própria", esta que se faz quando levantamos a cabeça e "escrevemos" um texto nela. Ainda que vagarosa, é essa leitura que, efetivamente, se torna pesquisa, pois é processada e dela pode sair a criação de algo, talvez, possa-se escrever e, quiçá, pensar... Nasce aí, uma nova relação com os textos.

Quando isso acontece, contudo, geralmente, o que há é apenas o prazer voluptuoso plenamente satisfeito da leitura (nesse momento, muitos de nós gostamos de tagarelar em aula ou nos corredores e bares sobre a ideia que tivemos, mas escrever é bem mais raro...). É preciso uma espécie de prazer atormentado capaz de provocar o desejo de escrever, a fim de fazermo-nos desejosos de escrever. Esse desejo é a energia vital no salto para o desconhecido, como diz João Cabral de Melo Neto, é "estar no extremo de si mesmo".

Ocorre que esse desejo não acontece para todos. Não são todos que, se Ihes acontece, assumem o desejo de escrever, que põem o escrever como algo pertinente na sua vida. Se assim fosse, não haveria muito mais leitores do que escritores... Ele, o desejo, talvez, seja o divisor de águas entre os pesquisadores/escritores e os leitores. Não há nenhum demérito, no entanto, de ser "apenas" um leitor, como afirmei antes, quando lemos há uma abertura de mundo e mais vida se produz em nossa vida. Aliás, talvez a maior parte dos leitores é feita de um tipo especial de escritores, os "escritores para si". Estes têm mais pudor que aqueles que tornam público suas escrituras, tal como pensa, outra vez, o poeta João Cabral de Melo Neto (apud BERNARDO, 1986):

Escrever é estar no extremo de si mesmo,

Revista Digital de Ensino de Filosofia - Santa Maria - vol.2., n.1 - jan./jun. 2016. 


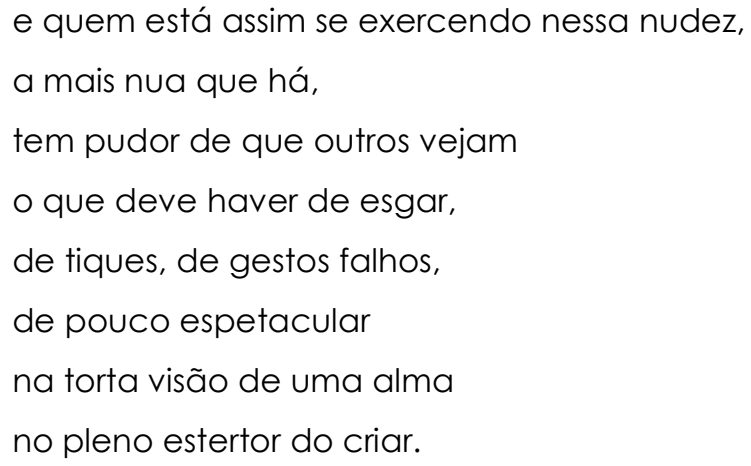

Leitores de livros de Filosofia, na certa, ouviram falar o que se tornou um jargão entre nós que nos ocupamos da Filosofia, a saber: que um filósofo, aquele que ama a sabedoria, está sempre em busca da Verdade, porque quer e ama o verdadeiro. Quanto mais tu fores adentrando no universo dos livros de Filosofia, no entanto, verás que não há acordo entre os filósofos a respeito do que seja a Verdade, inclusive poderás perceber, em algumas leituras, a recusa por esse objetivo final da Filosofia e, em lugar dele, a produção de sentidos e de valores para aquilo que criamos a fim de pensar o mundo. Importa, pois, acima de tudo, chegar a pensar com os autores que lemos, pois, como afirma Faguet:

Provavelmente, essa verdade foge de nós numa fuga eterna; provavelmente, os autores são inesgotáveis em razão do que têm e em razão do que, ao lê-los, neles colocamos. Mas o essencial é pensar. O prazer que buscamos ao ler um filósofo é o prazer de pensar, e desse prazer teremos desfrutado ao acompanhar todo 0 pensamento do autor e o nosso, mesclado ao dele, e o dele excitando o nosso e o nosso interpretando o dele e talvez o traindo; mas aqui se trata apenas de prazer [o prazer de pensar] (FAGUET, 2009 , p. 20).

Chegar a pensar é o maior desafio para qualquer um que se relaciona com a Filosofia. Tal fato, para mim, é a coisa mais rara. Se isso acontece uma vez não significa que se repetirá. E isso é válido para qualquer um, jovem ou velho, iniciante ou iniciado em Filosofia. Schopenhaver (2007, p. 47) tem razão quando afirma que "é possível a qualquer momento sentar e ler, mas não sentar e pensar". Para mim, 
no entanto, quando lemos, corremos um sério risco de chegar a pensar, especialmente se o que lemos não está relacionado com aquilo que estamos acostumados. Por isso, em mais um aspecto, discordo de Sócrates: ele afirma que o fato de a escrita se desenvolver, contém em si um risco, pois "um discurso sai a vagar por toda parte, não só entre os conhecedores, mas também entre os que o não entendem, e nunca se pode dizer para quem serve e para quem não serve" (PLATÃO, 1981, p. 152). De minha parte, "os que não entendem" podem passar a entender se lerem os discursos devagar, atenta e desconfiadamente, eles "servirão" para quem "levantar a cabeça", pois, se as bibliotecas são, como disse no início, a prova palpável da imensa generosidade da cultura, os livros são para qualquer humano que se interessar por eles. Por fim, as últimas palavras que ecoo são de um filósofo que muito me abre mundo e ajuda a viver, Gilles Deleuze. Para ele, um livro é como uma máquina sem significantes determinados, o único problema que cabe colocar frente a um livro é: ele funciona? Como funciona para você? E recomenda: "Se não funciona, se nada se passa, pegue outro livro" (DELEUZE, 1992, p. 16). Mas não deixe de procurar um livro que funcione!

\section{Referências}

ARISTÓTELES. Política. Tradução Mário da Gama Cury. Brasília: UNB, 1988.

AUSTER, Paul. A invenção da solidão. Tradução Rubens Figueiredo. São Paulo: Cia. das Letras, 1999. 
BÁEZ, Fernando. Los escritos perdidos de Aristóteles. In: Revista A parte rei, Madrid, vol. 24, 2000. Disponível em: <http://serbal.pntic.mec.es/ cmunozl 1/perdido.pdf>, último acesso em 22/05/2015.

BARTHES, Roland. O rumor da língua. Tradução Mario Laranjeira. São Paulo: Martins Fontes, 2004.

BERNARDO, Gustavo. Redação inquieta. Rio de Janeiro: Globo, 1986.

DELEUZE, Gilles. Conversações. Tradução Peter Pál Pelbart. São Paulo: Editora 34, 1992.

FAGUET, Émile. A arte de ler. Tradução Adriana Lisboa. Rio de Janeiro: Casa da palavra, 2009.

HEIDEGGER, Martin. Introdução à Filosofia. Tradução Marco Antônio Casanova. São Paulo: Martins Fontes, 2008.

PLATÃo. Fedro ou da Beleza. 2a. ed. Tradução Pinharanda Gomes. Lisboa: Guimarães, 1981.

SCHOPENHAUER, Arthur. A arte de escrever. Tradução Pedro Süssekind. Porto Alegre: L\&PM, 2007. 